\title{
Ludic Writing: Challenges in Gamifying English Creative Writing Class for Technopreneurial Purposes
}

\author{
SF. Luthfie Arguby Purnomo \\ theluthfie@gmail.com \\ IAIN Surakarta \\ Jl. Pandawa, Pucangan, Kartasura, Sukoharjo, Jawa Tengah, Indonesia
}

Received: January 12, 2017; Accepted: February 27, 2017; Published: March 3, 2017

\begin{abstract}
This paper, first of three research parts, attempts to describe the challenges English Letters at IAIN (Institut Agama Islam Negeri/State Islamic Institute) Surakarta faced in implementing gamification for technopreneurial purposes in regard to the transformation of a creative writing class into a ludic writing class, a gamification infused writing class. The challenges revealed are story-game script adaptation, integration portion, and monetization. Specific problems occur on each challenge. Story-game script adaptation exposes three problems namely (1) conditional branching system (2) visualization (3) copyrighted material issues (4) and writing mechanics adaptation. Integration portion challenge displays a problem on the insufficient alloted time for gamifying the creative writing class. Monetization challenge indicates three problems namely (1) the inexistence of monetization team, (2) the inexistence of institutional regulation for monetization management by study programs, (3) responses to gaming trends. Responding to these problems, solutions specifically designed based on the nature of the problems are implemented.
\end{abstract}

Keywords: ludic writing, gamification, English creative writing, technopreneurship

How to cite this paper: Purnomo, S. L. A. (2017). Ludic Writing: Challenges in Gamifying English Creative Writing Class for Technopreneurial Purposes. Journal on English as a Foreign Language, 7(1), 59-76. 
The idea of ludic writing roots from Homo Ludens, humans as a playful creature (Huizinga, 2014). As Homo Ludens, mankind lives in a ludic space, a system of experience incorporating concepts of game or gameplay and related experiences (Lindley, 2005), articulates their expressions through ludic linguistics, studying the relationship between language and play (Crystal, 1998), and expresses themselves in a ludic writing, a writing with pervasive structures of conditionality (Burn, 2008). These pervasive structures of conditionality, which Aarseth (1997) calls as traversal mode, Frasca (1999; 2007) signifies it as ludology, the study of mechanical emphasis that games should be treated as games, and Purnomo and Purnama (2015) indicate it to imply a ludorative act, an act gamers perform in regard to the mechanical and narrative elements of video games, are primarily found from video games. In the perspectives of creative writing, as suggested by Simons (2007), video games pertain the narratological nature of writing and thereby, in relation to the pervasive structures of conditionality, this narratological nature is the departing point for video games for being 'creative writing' and the departing point for the process of gamification.

Implementing gamification as a tool of integration between creative writing and video games indicates that the purpose of integration is to business, as suggested by Zicherman in Bogost (2013), Niman (2014), Reiners and Wood (2015), and Routledge (2016). Due to the business orientation gamification has, the process of integration has to conform to the market-driven form of integration. Suggested by Polanyi cited by Schaniel and Neale (2000), the integration forms, in regard to business aims, comprise redistribution, reciprocity, and exchange. In the context of gamification, redistribution is aimed at positioning certain administrative group as a publisher or a start-up. Reciprocity, in gamification, suggests game asset search and usage construct a game. Meanwhile, exchange refers to the commercial dissemination of the games to certain market. These three forms of integration imply that the integration of gamification, due to its business characteristics, is embodied into $\mathrm{x}$ and $\mathrm{y}$ axis relationship with $\mathrm{x}$ as the production and $\mathrm{y}$ the distribution (Figure $1)$.

High exchange refers to the segregation between developer and publisher while low exchange refers to the double functions of developer namely developer as developer and developer as publisher. In relation to English use in gamification, English dominantly functions as content in reciprocity and as media in redistribution and exchange. Since English functions dominantly as a content in reciprocity, its implementation consumes a larger portion than that of exchange and redistribution. Therefore, in integrating gamification in the context of creative writing, the portion of 
English, gamification, and business requires a lucid measure to disseminate the integration portion.

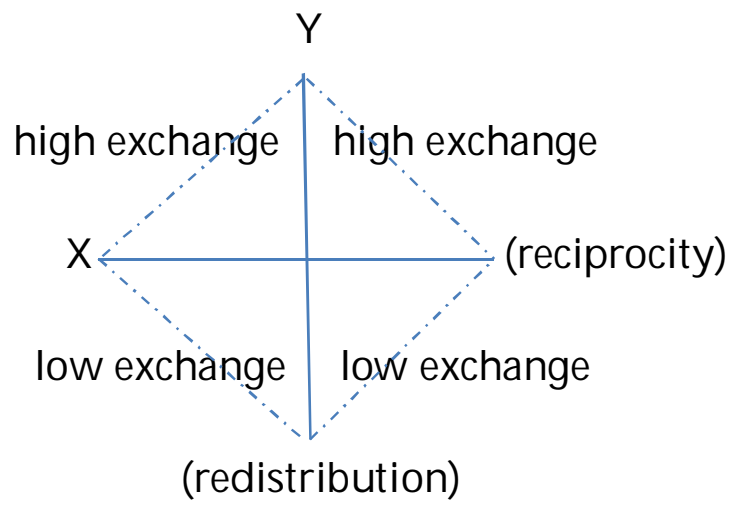

Figure 1. The Integration of Gamification (Constructed from Polanyi Cited by Schaniel \& Neale, 2000)

The aforementioned proceduralist view of integration, in regard to the transformation of creative writing into ludic writing, suggests that three considerations should be taken into account in the transformation process namely gamification, business dissemination, and integration portion. The relationship between these three components, in a larger scale, implies the presence of triple helix (Leydesdorff, 2013) of the relationship between creative industry practitioner in video games, the government through its initiatives on creative industry product dissemination, and university through its integration portion of theories and practices of gamification and its derivative business. These triangular components are the focus this paper attempts to examine in English Letters of IAIN Surakarta. The department since 2010 has transformed their creative writing classes into ludic writing with gamification as the medium. The games the students designed were not only disseminated for a scientific discussion but also for a technopreneurial purpose. In six years, the students have disseminated hundreds of physical copies through their selfmanaged expo they called FAIRY SALE (Simple Applications for Learning English), now changed into VELVET. The technopreneurship expo was exhibited like that of the professional expo with limitations on game and film products by the students. Aside of the expo as a conventional means of monetization, the expo also conducts seminar and workshop on technopreneurship to waive a network with potential clients with a priority on high school teachers. Starting from 2016, the department started an online expansion by disseminating the products to Google Playstore with the assistance from the alumni guild, EMILY-IKASKA (English Family-Ikatan Alumni Sastra IAIN Surakarta). This decision to disseminate the games by students via 
online is the primary highlight in online technopreneurship. The implementation of this specific technopreneurial purpose in English Letters department in regard to the transformation of creative writing into ludic writing class drew interests from the researcher to reveal possible challenges that might occur during the process of gamification integration in the department.

\section{METHOD}

This qualitative research was of descriptive manner. The procedures taken in conducting this research were first, adapting a short story and a legend into a game script. Second, the students of creative writing class underwent a 2D image based motion capture session (mo-cap) with the assistance from I After Smile Studio and Tentacle English Theater Club. Third, the students were taught how to operate visual novel template and RMVX provided by I After Smile Studio and how to import the 2D images into the template and RMVX. The fourth was informing EMILY-IKASKA about the gamification project and asking them to create a Google Playstore account. The fifth was uploading the project to Google Playstore and velis.xyz for three months alpha and three months beta. Sixth was holding a launching event to promote the games. Seventh was facilitating the students to form a start-up. These procedures were executed based on the integration of theory by Polanyi cited by Schaniel and Neale (2000) consisting of redistribution, reciprocity, and exchange, Aarseth's (1997) taxonomy theory, and Niman's (2014) gamification theory. Challenges occurring on the implementation of gamification in online technopreneurial purposes were noted and classified based on Polanyi's integration form. Data were acquired through observation during the progress of ludic writing execution and interviews to the students and the head of the department. The data were analyzed by employing content analysis as proposed by Spradley (1980) to reveal componential links between ludic writing, gamification, and product dissemination.

\section{FINDINGS}

The findings indicate that three significant problems occurred in the implementation process of gamification in English Letters department namely story-game script adaptation, integration portion, and monetization. In the story-game script adaptation, the students faced four problems: (1) conditional branching system (2) visualization (3) copyrighted materials, and (4) writing mechanics. In integration portion, the time alloted to implement the theory of creative writing, asset and template game design, and monetization theory is 
SF. Luthfie Arguby Purnomo

not sufficient. In monetization, reliance on self-marketing generates a significant problem on market coverage field.

\section{Story-Game Script Adaptation Challenges}

Conditional branching system, as suggested by Burns (2008) above, is the pervasive structure any games with narrative-driven genre have. This branching system requires the students to re-write the story as such that it has non-linear endings: true ending as narrated from the original story and alternate ending, self-created by the students. The problem occurs on the creation of alternate ending, one of ludic gameplay elements in games (Lizardi, 2014), as composing an alternate ending imposes the students to engineer the branching points first.

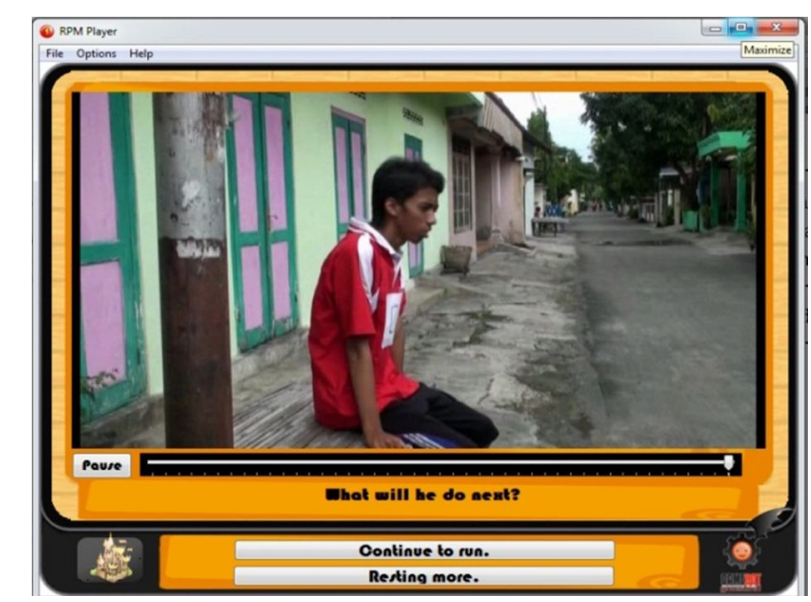

Figure 2. Branching system in Role Playing Movie

The screenshot in Figure 2 was a game designed in a film format, designed with the application called RPM (Role Playing Movie) by Gamebot, the previous name of I After Smile Studio. The game, re-titled The Solitude Runner, was an adaptation of Silitoe's The Loneliness of Long Distance Runner. As perceived from the above screenshot, the scene displays a conditional branching system from which the viewers have to select one of the options to progress to the next scene. Each option leads to a different ending: true and alternate. True ending refers to the ending sharing the closest conclusion as the original work while alternate endings suggest a different conclusion from the original work. These alternate endings are the source of branching problem the students faced. The problem students faced in branching the story is that in their opinions, branching a story means writing a new story with an already existing plot and this condition exposes a certain level of writing difficulty for them. The problem of alternate ending writing displays more complexities in terms of file size. Adding a complicated alternate ending means adding more file size to the game and big file size, in assumption, lessens the interests from Journal on English as a Foreign Language, 7(1), 59-76

Copyright @ 2017 by JEFL, p-ISSN 2088-1657; e-ISSN 2502-6615 
any potential users. In response to this problem, the students decided to shorten the alternate ending and preferred emphasizing on adapting the main story.

Adaptation also evokes aesthetics problems in relation to tone and style of the original and the adapted versions. In adapting a text-based literary work into a different type of text or digital text evokes the process, as Abbot cited by Hutcheon (2013) terms, of subtraction and contraction which involve the socalled surgical art. This process was also experienced by the students of English Letters 2010 who adapted Silitoe's work into a role playing a movie from which the viewers are able to decide to story plot and ending. In the adaptation version, the main story only focused on Smith and his past life and excluded other significant information like the setting as told on the novella and the additional branching story was far shorter than the main story. This condition, to some extent, contributed to the loss and gain in regard to the aesthetics of the original story. Its aesthetic values are further challenged by the necessity to adapt the story into Indonesian culture ranging from settings of places, costumes, actions, and accents. This whole process of alteration situated the students in a creative yet not lucrative condition as their focus was mostly spent to articulate how the adaptations might work. The visible impact of this process was their loss on branch making focus causing its alternate ending to appear trivial.

A different case is found from 2013 and 2014's students' film adaptations. Students from 2013 adapted a short story by Ryunosuke Akutagawa by the title In a Grove while 2014 adapted Maupassant's Suicide. Students of 2013 and 2014 did not do an adaptation of intrinsic elements only but performed adaptation on story formula also. By story formula adaptation refers to the adjustment of adaptation to the story formula of Indonesian soap opera (sinetron/film television). Departing from this formula, they claimed it would be easier for them to design the branch as, to some extent, soap opera story formula was familiar to them. The impact on the aesthetic value of this story formula adaptation is that the story and the plot appear to be local and domestic from which the students claimed that it would be suitable for the local viewers. To check the responses, the adapted films were taking part in English Letters film adaptation festival and the film adaptation of 2014 won Best Film while students of 2013 won Best Adaptation. This achievement, to some extent, indicates that their choice in adapting the story formula was of success. 

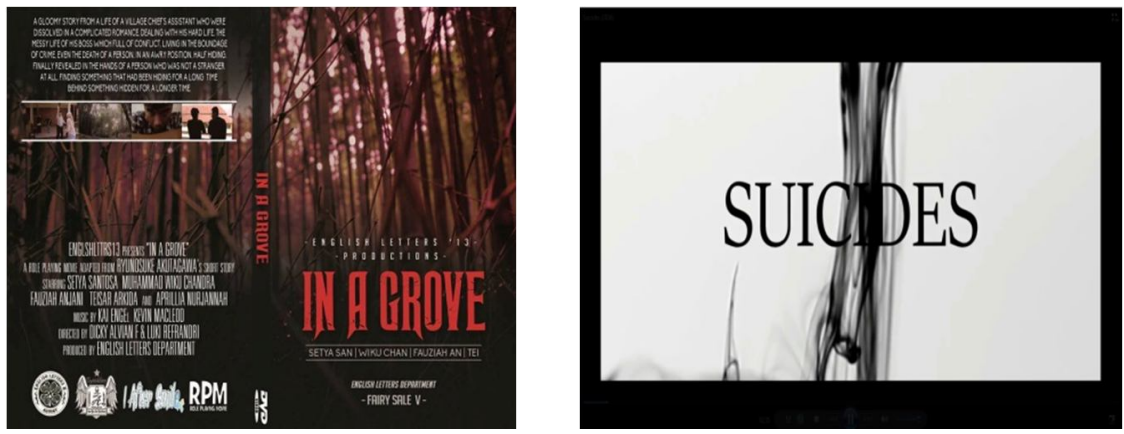

Figure 3. 2013's in a Grove and 2014's Suicides Film Adaptations

The difference between the two film adaptation is that 2013 still preserved the gamification feeling on the film while 2014 completely erased the gaming atmosphere from its film (Figure 3). English Letters 2013's in a Grove, as seen from its DVD box, employs RPM (Role Playing Movie) as its film and game genre. Similar to 2010 students, they also designed a branch for their story. In 2010's The Solitude Runner, the story branch, to some extent, was unable to represent the original story and to structurally link to the original ending, 2013 students' In a Grove adaptation employed a unique way to design a branch. They designed the original ending or true ending as an extended version with the alternate as the normal version. Executing this strategy, the viewers and the gamers are intrigued to reveal and watch the complete story by having the original ending. To do so, the viewers and the gamers are required to replay the RPM from the beginning and prompted to select different choices or paths to reveal the extended version. This concept of extended version through the presence of original or true ending is commercially and commonly exercised in gaming world and better known as replayability, the ability a game has to evoke the presence of re-experience (Fratessi, Griesbach, Leith, \& Shaffer, 2011) in regard to player's engagement (Giappone, 2015). These two aspects, reexperience and player's engagement, signify the necessity for a game to possess this replayability. In relation to English Letters students' RPM, adaptation plays a significant role in evoking this replayability since adaptation itself, in nature, is a bridge to draw viewers or gamers closer to their own culture.

The second problem on story-game script adaptation is visualization. Diegetic elements in the story the students engaged to are required to be visually transferred and formatted into non-diegetic elements and this necessity exposes an aesthetic visual problem. This visualization realization problem roots from the fact that the status of being a narrative a short story has is innately conflicting the necessity for a ludification. The following (Figure 4) might help clarify the statement. 


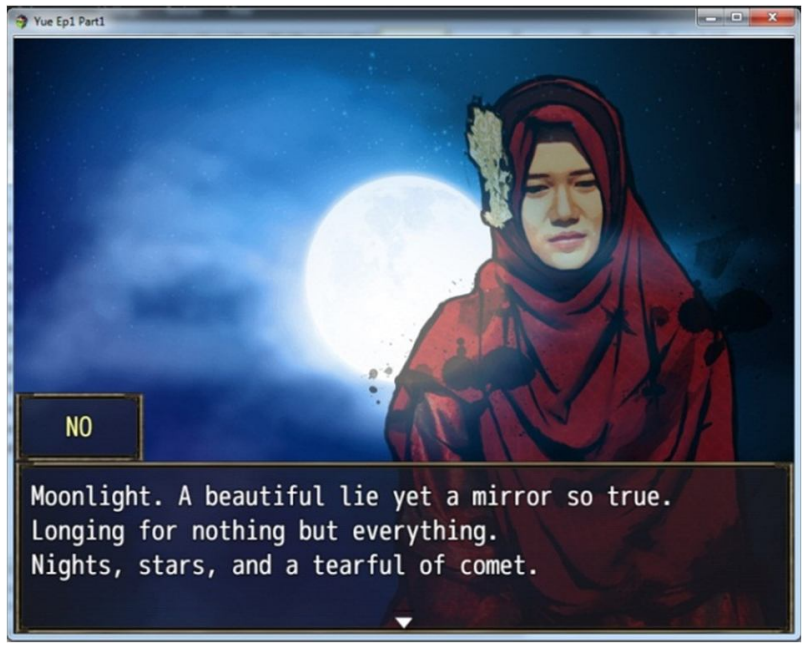

Figure 4. Visualization of Yue Episode 1: Wife of Night, Mother to Stars

The screenshot in Figure 4 was taken from Yue Episode 1: Wife of Night, Mother to Stars. This game by English Letters 2013 and 2014 is an adaptation of several historical events intertwined with the famous Chinese legend, Butterfly Lovers, as the plot axis. No (Nohime), the lady visualized above, was existent in the Japanese history in Sengoku era. In visualizing No, the students had to search for the historical potrait of the lady but in the searching process, it was revealed that there were plenty of popular potrayals of No in games and Japanese anime such as found in Koei's Samurai Warriors and Capcom's Sengoku Basara. Since the popular potrayals provided detailed visual information, the students preferred referring the lady from the game and anime to the historical potrayal. In both games and animation versions, No is mostly visualized as a lady with sharp eyes and enchanting demeanor. Departing from this commonly shared visualization, the lady as seen from the screenshot was selected to do the role. This transposition signifies the problem of transcoding, a change of code in adaptation (Hutcheon, 2012), in transpositioning historical stories to the game and in positioning the adaptation element by taking reference from similar code. Complexing the transcoding is the necessity to preserve Muslim identity in the game. To both preserve the identity of being a Muslim and project the cultural traits of the visualized character, the students dressed the actress in kimono with a modified veil.

Visualization, in games, refers also to the presentation of the user interface. In designing user interface, game designers have to concern on the ergonomic flow (Johnson \& Wiles, 2010), usability-oriented principles (Lee, Eastman, Taunk \& Ho, 2010), pedagogy centered for educational computer program (Khoo, 2011), and user interface tangibility (de Bérigny, Gough, Faleh, \& Woolsey, 2014) of the interface for the users to interact. In the case of ludic 
writing class in English Letters at IAIN Surakarta, the presence of templates was proven to be assistive to the students as they were not disturbed by the necessity to design the user interface themselves. The game templates provided by the department convey the whole system of visual novel gaming namely character design, narrative system, environment and VFX design, BGM and SFX, the user interface and Graphic User Interface (GUI) design. Both RPG Maker VX and Livin Maker 2 are accessible by the students to construct a game with the provided templates as the basis. The problem the students faced was integrating the whole system of visual novel elements into a single entity from which the gamers are able to immerse themselves into the visual novel gameplay. This immersion, in regard to the stereotype visual novel bears, also exposes a significant problem for the gamers.

The visual novel is stereotyped as a love story-attached game with girls in their revealing outfits as a fan service tool. This stereotype contributes to the construction of affective ludology, affective measurements of player-game interaction (Nacke \& Lindley, 2010), to which the gamers are attached and expected to evoke certain emotions. In the case of visual novel stereotyped as such, gamers, upon recognizing a title under this genre, are suffering from preliminary affective ludology that they would find girls in revealing costumes on the game. When this expectation slides from reality, the expected affection would not occur and to some extent influence the immersion level of the gamers into the games. In the case of visual novel designed by the students of English Letters IAIN Surakarta, the genre does not follow the 'supposed' visual novel instead they wrapped the genre in a serious tone and combined it with Role Playing Games to add action game flavor into the games.

The third problem is copyright material. The burdens of ludic writing the students bear as perceived from the necessity of composing a conditional branching system and visualization demands a technical friendliness from the game mechanism to light the burdens. To do so, it is unethical if the diegetic and non-diegetic elements are of copyright violation and thereby in the ludic writing class, the students are strongly encouraged to maximize free game assets on the internet. Unity asset store, sprite resource, Kevin McLeod background music (BGM) and other free asset providers are free for use with certain conditions. 


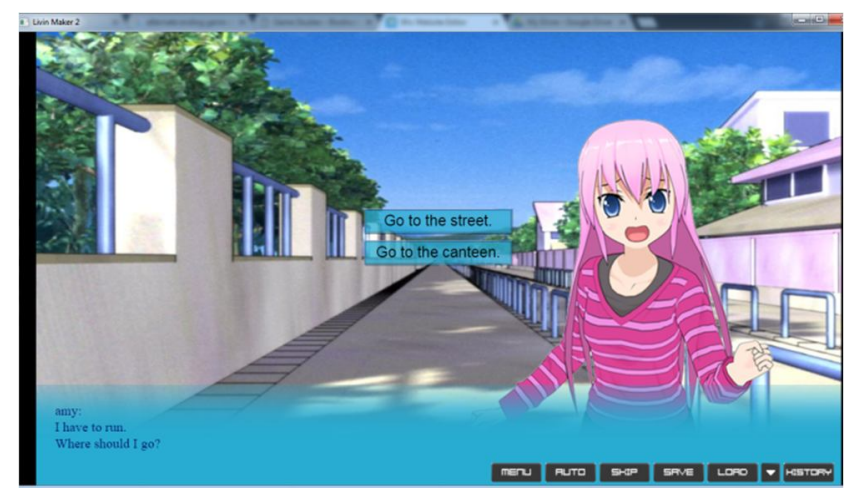

Figure 5. 2D Assets to Design a Visual Novel

The screenshot in Figure 5 is of After School, a material template to design a visual novel from English Letters and I After Smile. The backgrounds are of free assets without any conditions for commercial use and thereby the users are allowed to make any changes to the pictures. Problems occur in assets with non-commercial use conditions. Due to the necessity of business in gamification context, the students had to surf the internet to find assets with simple conditions for commercial uses like quoting the names of the designers. To palliate this problem, in the ludic writing class, a list of free asset providers was provided.

The fourth problem is writing mechanics adaptation. The adaptation of novella or short story into a film and role-playing movie format as found in The Solitude Runner, In a Grove, and Suicides and the adaptation from the script into computer script as found from Yue: Wife of Night, Mother to Stars by English Letters 2013 and 2014 generate challenges in their writing mechanics. Novella and short story have a prosaic language mechanically different from film and game scripts that tend to be dramatic in their writing mechanism. This challenge along with the story adaptation, in the context of ludic writing in English Letters IAIN Surakarta, becomes more complicated when the script is not only textual-based but also ergodic-based, literature which requires traversal function to assess it (Aarseth, 1997; Eskelinen, 2012) like those of video games. In transferring the script into the ergodic-based script, though the transfer is mediated through video game template, the students had to master a simple coding to realize it.

The simple coding on Livin Maker 2 is mainly classified into copy and paste and erase and replace. In copy and paste, the coders are asked to copy the existing codes and paste them to a newly designated place while in erase and replace, the coders are prompted to erase the existing codes and replace them with their own. The copy and paste features are designed to function mostly for creating story branches while erase and replace features are to design supporting 
game elements like BGM, SFX, pictures, and images. The challenges the students faced in exporting the text formats into code formats were (1) adaptive aptitude to codes (2) code detail and (3) error management.

Students required different length of time to adapt themselves to the codes of Livin Maker 2, the program English Letters at IAIN Surakarta designed for their students, and thus, to ensure that the game adaptations were completed on time, the lecturers grouped them into teams with the head of each team selected for their good aptitude in transferring story to codes. The purpose of this team making is to elicit peer learning and specific job dissemination from which the products would arrive on time when the technopreneurship expo was in progress. Aside from the adaptive aptitude, the necessity to pay attention to the detail of the codes forced the students to check the codes thoroughly. Though the codes were designed to conform to users with no programming background, the students still found that the time to check the code detail was time-consuming.

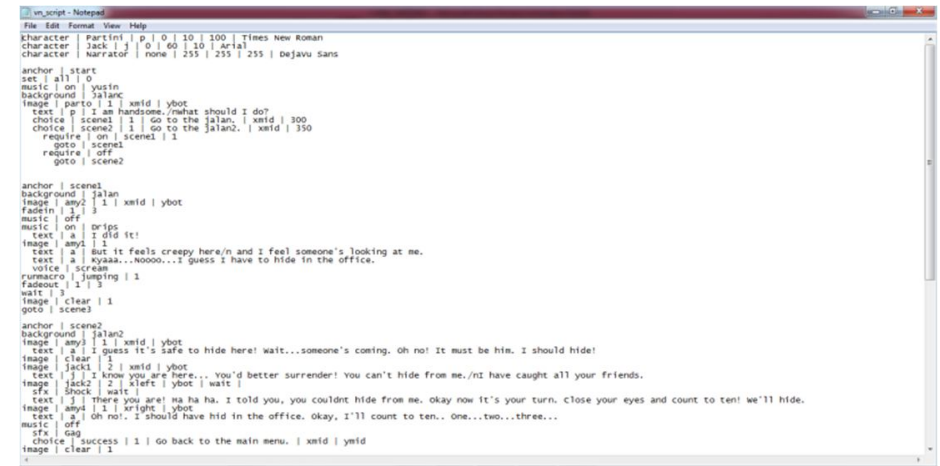

Figure 6. Codes in Livin Maker 2

As seen from the screenshot in Figure 6, details like | signs, the adjacent uses of word and number, spaces, and logical signs opened challenges for the students to adapt themselves with these details. When the students transferred their story into a game format, they had to carefully integrate it with the codes. Thereby, when they wanted to transfer "Come hither, O, harbinger of chaos!", ordered Julius for example, the coding would look like as follow:

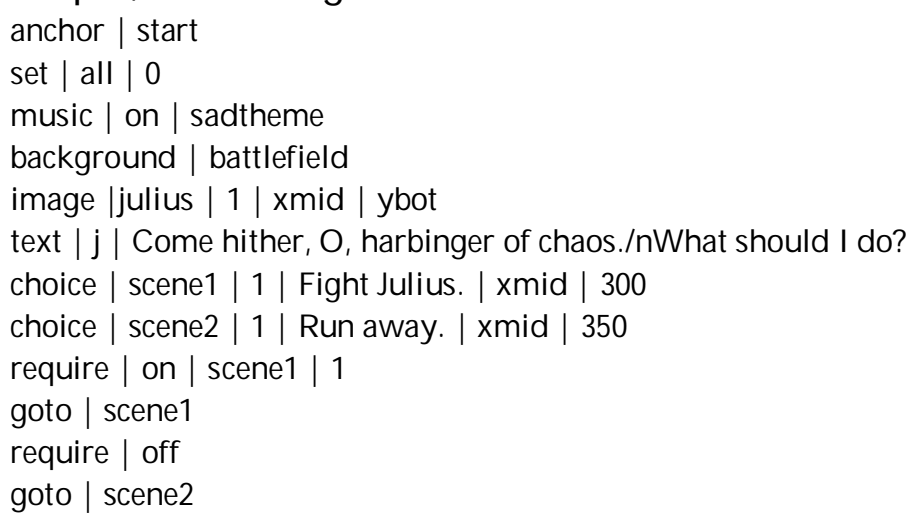

Journal on English as a Foreign Language, 7(1), 59-76

Copyright $\odot 2017$ by JEFL, p-ISSN 2088-1657; e-ISSN 2502-6615 


\section{SF. Luthfie Arguby Purnomo}

The multimodal aspects of a game require the students to elaborate the story narrative into a film-esque construction where audio and visual elements are exploited to fit the narrative frame. The adaptation was turning more complex and sophisticated when the students were required to design a branch as they had to adapt two narrative parts into a single code implying that the code sheet would be much longer. To cope this challenge, the students disseminated their coding in a peer discussion to their team mates per scene and compiled the scenes and sheets together on a single code sheet.

Issues following an inability to adapt to the aforementioned code details are of technical ones. Technical errors like story branch malfunctions, image stacks, and even the worst being the game did not run. When these errors took place, they rechecked the codes from the start as instructed by the game design manuals and tutorials given by the lecturers. If they were unable to fix the problems, they did a peer discussion to solve the problems with other teams. If the problems still persisted, they contacted the lecturers to ask some solutions.

\section{Integration Portion Challenges}

Three areas were to cover in implementing gamification in online technopreneurial purposes: story writing theory, game design, and monetization theory. In fourteen meetings, those three areas are required to accomplish. In English Letters department, this integration portion is regulated on DISC (Dissemination Integration for Syllabus Configuration), a system to measure the weight of each course with dissemination as the central axis.

DISC classifies courses into three types namely Task, Product, and Project. The classification is based on Weight $(\mathrm{W})$, Height $(\mathrm{H})$, and Freight $(\mathrm{F})$ formula. Weight is the theory loads the students need to learn. Height is the level of probabilities a course has in yielding a product. Freight is the total meeting alloted for a semester. Through the combination of $\mathrm{W}, \mathrm{H}$, and $\mathrm{F}$, certain numerical quantification is formulated and departing from the quantification, a certain feature of courses is visible. Tasks are courses designed with a heavy portion of theory. The final assignments of task courses are analytical papers. Products are courses designed to yield a product for the final assignment. Meanwhile, Projects are courses designed not only to create a product but also to market the products to the public. Creative writing class, based on DISC, belongs to Project type requesting the lecturers to run story writing theories for three meetings, game template operation for two, prototyping (alpha, beta, and closed beta) for three, content review for one, monetization theory for one, offline dissemination for three, and online for one day (packaging, compiling, and uploading). 
In the research, the regulation DISC has mandated was violated due to technical problems in the prototyping and online dissemination phases. One of these technical problems is Google policy adjustment. Due to the necessity to conform to Google policy, the prototyping flow is hindered and it disarrayed the creative cycle of game design. To solve this problem, extra meetings are added and this implies the emergence of more working loads from the students.

\section{Monetization Challenges}

Monetization, how games make money, is classified into five methods namely retail purchase, in-game microtransactions, digital download, subscription model, and indirect monetization (Fields, 2014). In regard to the research focusing on online technopreneurial purposes, the retail purchase is not possible due to its complicated business scheme and its reliance on physical distribution of the games. Visible and probable monetization methods for a digital product in this research are the last four especially the last one.

In-game micro transcation is possible but visual novel, the genre selected in this research, opens no chance for microtranscation commonly identical to MMOG (Massively Multiplayer Online Games). The absence of institutional server for the visual novel created by the students leaves no opportunity for the students to engage in this monetization method. The third method, digital download, has a high probability as English Letters department has its own but two problems emerge from this method in regard to the department. First is the absence of monetization team administering the digital download distribution ranging from marketing to profit sharing management. Second is the absence of institutional regulation administering the legal standing of monetization in state-owned educational institution. Due to those problems, the digital download method applied by the students and the department was not monetized. The products were featured in velis.xyz and available for free to download. The fourth method, the subscription model, is not possible to be implemented since it technically applies to AAA games and companies which already leave a branding mark in the gaming industry. The last method, indirect monetization, which relies on ads is the only possible monetization method the students and the department could do. To do so, the games designed by the students, mechanized for PC users, have to be apk-ed to make it possible for android and iOS market.

Adding ads to the games exposes a challenge on the persuasive level to click the ads and the necessity to make the game viral deeply influenced by trends. This problem of the trend is a concern for the ludic writing class in the department because trends are dynamics in nature and to respond these dynamics, in regard to educational purposes and resources, requires a complex 
SF. Luthfie Arguby Purnomo

preparation. To solve these problems, monetization management by external parties is required. By external parties refer to persons or companies working in game marketing, featuring, and promotion especially for game apps. One of the examples is PlayPlayFun. This site offers a chance for any games to be promoted and featured on its page in an exchange of profit-sharing. Due to its massive coverage, the chance for the student's games to reach a global audience is high. This external party involvement plays a significant contribution to the follow-up program of gamification namely start up or indie company establishment by the students. This follow-up program is the focus of the second part of this research. A unique finding in follow-up program, in regard to monetization, is the establishment of an indie game developer by five students of 2013. They, due to their interests and capabilities in digital literature, were supported by English Department to establish an indie game developer. This establishment was triggered by the strategic policies of the local government of Surakarta in supporting and financing start ups especially those established by youths and college students. Supported by the department and the government, the students built an indie game developer by the name Pentaguns, focusing on creative digital literature.

The above case of follow-up program to expand and enlarge monetization opportunities, in the perspectives of gamification, is the realization of triple helix relationship between university, game industry, and government.

\section{DISCUSSION}

In Aarseth's textonomical perspectives, primarily emphasizing the importance of user's function (1997), and Polanyi's integration forms, gamification for technopreneurial purposes in the context of ludic writing is structured on four levels namely interpretive, explorative, configurative, and textonic. In the interpretive level, the gamification circumnavigates on the narrative related works such as story adaptation and visualization to which interpretation of certain narrative dominates the process. In the explorative level, the gamification operates on the selection of certain tools to design games. The selected tools have to conform to the resources the users have. In the configurative level, the narrative and tools are integrated to the ludic writing class and departing from this integration, game monetization and user's responses are assumed to contribute to the emergence of changes in the games to meet the user's demand. In relation to Polanyi's integration forms, these four level of user's function operates on redistribution, reciprocity, and exchange. The following illustration (Figure 7) might clarify the statement. 


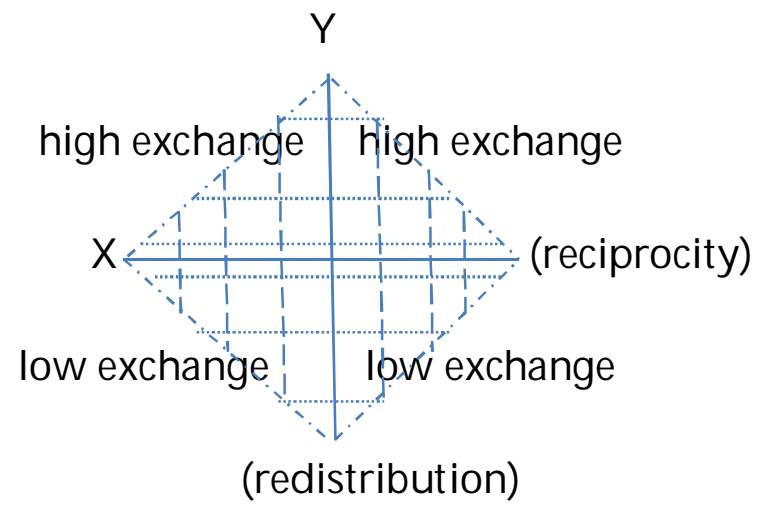

interpretive, explorative, and configurative

---- : textonic

Figure 7. Relationship Between User's Functions and Integration Forms

As seen from Figure 7, interpretive, explorative, and configurative user's functions dominate the operation of reciprocity integration form. This condition is logical in gamification context since writing and game design are the primary focus to yield a ludic creative product in a game format. Meanwhile, textonic level experiences a unique occurrence since this level experiences a dual occurrence on redistribution and exchange. This condition is logical as monetization and marketing are the basic nature of technopreneurship, especially in the gaming industry. This relationship signifies that production level in ludic writing consumes orthotic portions while dissemination consumes prosthetic portions. By orthtotic portions mean that certain gaming tools like templates and assets are assistive tools that support the gamification integration but not replacing the gamification integration process. Meanwhile, by prosthetic portions imply that the whole process of dissemination is replaceable by certain tools. The presence of game monetization and promotion sites is the example of this prosthetic portion.

In relation to the research findings, these orthotic portions are perceptible from the dominant challenges on reciprocity on story-game script adaptation and integration portion while the prosthetic portions are seen from the monetization challenges. The domination of narrative-related challenges conforms the dominant operation of reciprocity as suggested from the chart while the less domination of marketing-related challenges indicate the complex nature of marketing operation in redistribution and exchange forms. 


\section{CONCLUSION}

The gamification for online technopreneurial purposes in regard to the ludic writing class in English Letters department exposes three challenges namely story-game script adaptation, integration portion, and monetization. Each challenge displays specific problems. The first challenge, story-game script adaptation, shows three problems: (1) conditional branching system (2) visualization (3) and the issues of copyrighted materials. The second challenge, integration portion, displays a problem on the insufficient alloted time. The third challenge, monetization, indicates three problems. They are (1) the inexistence of monetization team administering the digital download distribution ranging from marketing to profit sharing management, (2) the inexistence of institutional regulation administering the legal standing of monetization in state-owned educational institution, (3) responses to gaming trends.

The problems occurring from the challenges are specifically addressed by solutions conforming to the nature of the problems. In the story-game script adaptation, the problem of conditional branching is solved by limiting and shortening the story branching. Visualization realization is solved by referring to popular potrayal of certain characters. Copyrighted material issues are resolved by utilizing free game assets and templates. Writing mechanics are settled by tutorials and peer discussions. In integration portion, modification of meeting as regulated by DISC is exercised to solve the insufficient alloted time. In monetization challenge, the three problems are resolved by involving external game marketing party to handle the promotions. Departing from these problems and resolves, the integration of gamification and creative writing to yield a ludic writing class requires seven considerations for implementation namely (1) literary materials to adapt into game format, (2) game templates and platforms to which the games are designed to, (3) supporting hardware and software, (4) student grouping, (5) offline and online dissemination, (6) monetization management, and (7) indie company follow ups.

\section{REFERENCES}

Aarseth, E. (1997). Cybertext: perspectives on ergodic literature. Baltimore: The John Hopkins University Press.

Bogost, I. (2013). Exploitationware. In rhetoric/composition/play through video games (pp. 139-147). Palgrave Macmillan US.

Burn, A. (2007). Writing'computer games: Game literacy and new-old narratives. L1-educational studies in language and literature, 7(4), 45-67.

Crystal, D. (1998). Language play. University of Chicago Press. 
SF. Luthfie Arguby Purnomo

de Bérigny, C., Gough, P., Faleh, M., \& Woolsey, E. (2014). Tangible user interface design for climate change education in interactive installation art. Leonardo.

Eskelinen, M. (2012). Cybertext poetics: The critical landscape of new media literary theory. Bloomsbury Publishing USA.

Fields, T. (2014). Mobile E social game design: Monetization methods and mechanics. CRC Press.

Frasca, G. (1999). Ludology meets narratology. Parnasso\#3: Helsinki. Retrieved from http:/ /www.ludology.org /articles/udology.htm.

Frasca, G. (2007). Play the message: Play, game and videogame rhetoric (Published Doctoral Dessertation). Retrieved from http://www.ludology.org articles/udology.htm.

Frattesi, T., Griesbach, D., Leith, J., Shaffer, T., \& DeWinter, J. (2011). Replayability of video games. IQP, Worcester Polytechnic Institute, Worcester.

Giappone, K. (2011). Self-reflexivity and humor in adventure games. Game Studies, 15(1).

Huizinga, J. (2014). Homo ludens ils 86. Routledge.

Hutcheon, L. (2012). A theory of adaptation. Routledge.

Johnson, D., \& Wiles, J. (2003). Effective affective user interface design in games. Ergonomics, 46(13-14), 1332-1345.

Khoo, B. K. (2011). User interface design pedagogy: A constructionist approach. International Journal of Information and Communication Technology Education (IJICTE), 7(1), 1-10.

Lee, G., Eastman, C. M., Taunk, T., \& Ho, C. H. (2010). Usability principles and best practices for the user interface design of complex 3D architectural design and engineering tools. International journal of human-computer studies, 68(1), 90-104.

Leydesdorff, L. (2013). Triple helix of university-industry-government relations (pp. 1844-1851). Springer New York.

Lindley, C. A. (2005). The semiotics of time structure in ludic space as a foundation for analysis and design. Game Studies, 5(1), 2005.

Lizardi, R. (2014). BioShock: Complex and alternate histories. Game Studies, 14(1).

Nacke, L. E., \& Lindley, C. A. (2010). Affective ludology, flow and immersion in a first-person shooter: Measurement of player experience. arXiv preprint arXiv:1004.0248.

Niman, N. (2014). The gamification of higher education: developing a game-based business strategy in a disrupted marketplace. Springer. 
Purnomo, S. L. A., \& Purnama, S. L. S. (2015). Ludorative acts: Questioning the existence of performative acts in video games. International Journal, 3(2), 73-81.

Routledge, H. (2016). Why games are good for business: how to leverage the power of serious games, gamification and simulations. Springer.

Schaniel, W. C., \& Neale, W. C. (2000). Karl Polanyi's forms of integration as ways of mapping. Journal of Economic Issues, 34(1), 89-104.

Simons, J. (2007).Narrative, games, and theory. Game studies, 7(1), 1-21.

Spradley, J. P. (2016). Participant observation. Waveland Press.

Wood, L. C., \& Reiners, T. (2015). Gamification. In Encyclopedia of Information Science and Technology, Third Edition (pp. 3039-3047). IGI Global.

\section{Author's Brief CV}

SF. Luthfie Arguby Purnomo. My research interests revolve around gamerelated studies. Penerjemahan Video Games (Video Game Translation) Mendesain Media Pembelajaran Bahasa Inggris Berbasis Video Games (Designing Video Games Based Language Learning Media), Digital Game-Based Language Learning with RMVX, Edu Games $x$ Edutainment Games: the Design are some publications I authored. I also have localized and designed games, software, and apps for I After Smile Studio. 